\title{
Teaching and Learning Using Whatsapp: English Teachers' Perception Title
}

\author{
Yusuf Al Arief ${ }^{1}$, Rizky Amelia ${ }^{2}$, Eka Puteri Elyani ${ }^{3}$ \\ 1,2,3 Universitas Lambung Mangkurat \\ 1yusufalarief@ulm.ac.id, 2rizky.amelia@ulm.ac.id, ${ }^{2}$ eka.elyani@ulm.ac.id
}

\begin{abstract}
Social media has become part of the lives of Indonesian teenagers today. Referring to a survey conducted by the Indonesian Internet Network Organizing Association (APIII) in 2017, young people dominate the internet users in Indonesia to adults with a percentage of $75.50 \%$ in the age range of 13-18 years, and teachers must deal with this fact. The researchers were interested in using teenagers' addiction to these gadgets to support the learning process. In this study, researchers used descriptive qualitative methods and took English teachers in Banjarmasin as research. The research was conducted by holding social media training, focusing on WhatsApp to learn English. Next, the researchers asked the subjects to use WhatsApp in the teaching and learning process. Next, researchers distributed questionnaires to figure out the perception of teachers. As a result, it was found that: 1) WhatsApp was very useful as a learning medium, 2) Students were motivated to follow the learning process because they used something they like, 3) WhatsApp can also promote more interaction between students.
\end{abstract}

Keywords: Whatsapp, English learning, perception

\section{INTRODUCTION}

Social media has become part of the lives of Indonesian teenagers today. According to a survey by the Indonesian Internet Network Organizing Association (APJII) in 2017, internet users in Indonesia are dominated by young people to adults with a percentage of $75.50 \%$ in the age range of 1318 years. In 2017, the total of internet users had reached 143.26 million. It increased compared to the year before, namely in 2016, which was recorded at 132.7 million. The data results from a survey conducted by the Indonesian Internet Service Providers Association (APJII) ${ }^{1}$. APJII Secretary General Henri Kasyfi Soemartono explained that internet users in 2017 included 54.68 percent of Indonesia's whole population, 262 million users. Referring to gender, the internet user composition in Indonesia is $\mathbf{5 1 . 4 3}$ percent for males and $\mathbf{4 8 . 5 7}$ percent for females. As many as 16.68 percent of the users aged $13-18$ years, and 49.52 percent aged $19-34$ years. Whereas the internet users percentage aged, 35-54 years was about 29.55 percent. Internet users aged 54 years and above was about 4.24 percent. The internet users who graduated from junior high school or equivalent was about 48.53 percent, and elementary school graduates, or equivalent, was about 25.10 percent.

\footnotetext{
${ }^{1}$ https://apjii.or.id/survei
} 
Primarily, the internet is used to chat. Daily Social Survey ${ }^{2}$ conducts surveys related to the most widely used applications in 2017. Some survey findings include:

1. $97.24 \%$ of survey respondents stated that they used WhatsApp, and $61.81 \%$ said that WhatsApp is the instant messaging application they use most often.

2. The four mobile instant messaging applications used by the respondents were WhatsApp (97.24\%), LINE (88.49\%), BBM (85.82\%), and FB Messenger (77.26\%)

3. Only $0.76 \%$ of respondents said they relied on Telegram for instant messaging

4. The number of respondents who separate chat apps based on communication (for jobs, for families) amounted to $40.19 \%$, only slightly less than those who did not separate $(59.81 \%)$.

5. Quite a several respondents (90.48\%) agree that we need a chat application created explicitly by and managed by an Indonesian company.

In Indonesia, WhatsApp is the most popular application ${ }^{3}$. In August 2016, several domestic digital and advertising company associations officially partnered with comScore research company to create an Online Audience Measurement Standard. comScore is expected to provide data on the number of visitors from each site and mobile application in Indonesia, like Nielsen's rating for television media. On March 29, 2017, comScore also presented their first report. The report was taken based on January 2017 data.

\begin{tabular}{|c|c|c|c|}
\hline \multicolumn{4}{|c|}{$\begin{array}{l}\text { Top } 10 \text { Apps from Mobile Devices in Indonesia } \\
\text { January } 2017 \\
\text { Total Indonesia - Age } 18+\text {, Mobile App only } \\
\text { Source: comScore Mobile Metrix }\end{array}$} \\
\hline \multirow[t]{2}{*}{ Rank } & \multirow[t]{2}{*}{ App } & \multicolumn{2}{|l|}{ Total Mobile } \\
\hline & & Total Unique Visitors (000) & 96 Reach \\
\hline & Total Internet: Total Audience (Mobile App only) & 46,130 & 100.0 \\
\hline 1 & Google Play & 44,292 & 96.0 \\
\hline 2 & WhatsApp Messenger & 35,799 & 77.6 \\
\hline 3 & YouTube & 35,627 & 772 \\
\hline 4 & BBM & 34,748 & 75.3 \\
\hline 5 & Googie Search & 30,442 & 66.0 \\
\hline 6 & Gmal & 28,584 & 62.0 \\
\hline 7 & Line & 27,613 & 59.9 \\
\hline 8 & Instagram & 23,876 & 51.8 \\
\hline 9 & Facebook & 22,268 & 483 \\
\hline 10 & Google Maps & 20,865 & 452 \\
\hline
\end{tabular}

Graph 1 Top 10 Apps from Mobile Devices in Indonesia

Because the internet, especially chat applications like WhatsApp, has become a part of children's lives and adolescents in Indonesia, efforts are necessary to increase awareness, knowledge, and skills to use the internet safely. This study suggests that parents and teachers supervise and assist their children in digital activities and engage in them, and teachers have to

${ }^{2}$ DailySocial Instant Messaging Survey 2017

${ }^{3}$ https://id.techinasia.com/comscore-whatsapp-adalah-aplikasi-terpopuler-di-indonesia 
deal with this fact well. Based on this problem, the researchers were interested in using teenagers' addiction to these gadgets to support the learning process.

This research was different from other research in the same field since The other research concerns more with the applications that can be used in the EFL classes. In contrast, researchers focused on the teachers' perception of WhatsApp, which will be the note for the researchers as lecturers for sharing teaching tools with teachers and teachers as the teaching reflection in the EFL classroom.

\section{Blended Learning}

Currently, one of the most widely used learning is blended learning. Blended learning is the educational approach that compiles online educational material and online interaction with traditional classroom methods of traditional place-based. It calls for the bodily presence of each instructor and student, with a few features of student management over time, place, direction, or pace. (Mims-Word, 2016)(Friesen, 2012)(Knewton, n.d.)(Staker \& Horn, 2012) While scholars still join "brick-and-mortar" colleges with the instructor exists, direct lecture room performances are mixed with computer-mediated pursuits concerning content material and start. (Strauss, 2012) mixed discovering is additionally used in professional advancement and education settings. (Lothridge, 2013)

combined researching is exceptionally context-dependent. Hence, commonplace attention of it is hard to come by.(Moskal, Patsy; Dziuban, Charles; Hartman, 2012) a few signs that a lack of consensus on a hard definition of combined studying led to problems in analysis on its effectiveness. (Oliver M, 2005) though, a 2015 meta-analysis which traditionally looked back at a finished evaluation of evidence-based historic replica round combined researching, found cohesions in giving a definition that combined researching was thought of a mixture of traditional the direct modes of teaching with online modes of studying, drawing on technology-mediated teaching, where all members in the researching system are parted by the distance a few of the time." (Siemens, G., Gašević, D., \& Dawson, 2015) This document additionally discovered that all of these evidence-based experiences determined that the student fulfillment was more advantageous in mixed discovering studies when in contrast to both fully online or fully offline getting to know understandings. (Siemens, G., Gašević, D., \& Dawson, 2015) mixed discovering is each piece used in the same as customized education" (Bray, 2012) and distinguished teaching. (Dale, 2014)

Combined instruction is reportedly more effective than only direct or simply online categories. combined researching methods can additionally result in high degrees of student fulfillment more operative than direct learning. (Saritepeci, 2015) Using a mixture of electronic instruction and one-on-one face time, scholars can work on their own with new ideas that accessible lecturers up to flow into and individual agreement scholars who may need personalized attention. "Rather than gambling to the lowest average denominator - as they would in a traditional lecture room - academics can now modernize their teaching to assist all scholars to grasp their full talents. Proponents of the mixed discovering claim that integrating the "asynchronous Internet verbal exchange era into better education classes serves to "facilitate a simultaneous impartial and collaborative researching experience." (Garrison, D. R.; Kanuka, 2004) 
This combination is a big contributor to student self-importance and achievement in such lessons. The use of promoting and communique applied sciences has been found to progress student defiance toward education. (Alexander, 2010) By incorporating counsel generation into class initiatives, communique among teachers and part-time scholars has greater, and scholars were able to compare better their knowledge, of course, dresser in no way the use of "computer-based qualitative and quantitative evaluation modules." (Alexander, S. \& McKenzie, 1998)

Combined researching additionally has the knowledge to minimize academic chicken, though a few dispute that mixed researching is inherently less expensive than traditional schoolroom learning. (Conference overseas, 2016) combined getting to know can lesser charges by putting lecture rooms in the online area, and it well-nigh substitutes costly textbooks with digital units that scholars often deliver themselves to class. E-textbooks that can be retrieved digitally might additionally assist in pressuring down textbook finances. Supporters of mixed research cite the opportunity for information assortment and modification of teaching and evaluation as two significant advantages of this approach. (Harel Caperton, 2012) combined discovering comprises utility that mechanically collects student information and measures tutorial machine, offering lecturers, scholars, and fogeys especially scholars information. Often, checks are mechanically scored, offering instances comments.

Student logins and work times were additionally examined to make sure responsibility. colleges with mixed researching courses may additionally select to reallocate components to raise student fulfillment outcomes. (Jacob, 2011) scholars with particular abducted or pursuits out of the available curricula use tutorial era to develop their abilities or surpass score restrictions. (Ingfei Chen, 2014) Combined studying makes it possible for customized education, changing the model where an instructor stands in entrance of the schoolroom, and everybody is expected to stay at the same pace. Combined researching permits scholars to effort at their step, making sure they comprehend entirely new ideas earlier than moving on." A schoolroom atmosphere that contains mixed studying calls for newcomers to show more independence, self-regulation, and freedom to succeed. If academics are glad about a form of primary program direction earlier than presenting combined studying suggestions, it can better arrange scholars to think assured circumnavigating the alternative accessories and a better experience of independence. (Mims-Word, 2016) a few online establishments attach scholars with teachers in no way web convention generation to form an email correspondence schoolroom. These and many others copy many of the applied sciences that have promoted online classes at the college level. A few benefits of combined getting to know, especially at a Kindergarten to grade 12 level of education, can be discovered under the typical concept of the academic era. It is additionally one of the most effective ways for customized discovering at scale. Mixed discovery helps the criteria use as a means to accomplish quality and affluence of use. It contains dissimilar types of criteria: interoperability criteria like the SIF requirement from $\mathrm{A} 4 \mathrm{~L}$ or the discovering gear Interoperability requirement from IMS international Consortium or tutorial criteria comparable to state criteria and average middle State criteria, that inspire the combination of generation into a diversity of subjects.

A studying control scheme, or confederation of methods, enables progress a better think for an online group where negotiations can be seized to assist students. (Heinze, 2005) This computer-generated discovering ambiance enables-attach professors with scholars deprived of 
bodily being present; therefore, making this a 'virtual cafe.' Numerous colleges use this online instrument for online categories, classwork, question \& reply boards, and other school-related work. Some studies mixed getting to know yielded practical consequences from the online group (Bradford, Porciello, Balkon, and Backus, 2007). Such effects were in contrast and confirmed similar effects from the Alcoholics nameless and Weight Watchers. (Heinze, 2005)

The benefits of combined research are established on the excellence of the courses being applied. A few alerts of excellent mixed studying courses are "facilitating student studying, speaking concepts comfortably, demonstrating an interest in discovering, organizing comfortably, appearing to appreciate for scholars, and assessing development fairly." (Hartman, J.; Moskal, P. \& Dziuban, 2005).

\section{Synchronous Learning}

Based on its implementation, combined discovering can be classified as Synchronous and Asynchronous discovering. In this paper, the researcher centered on Synchronous getting to know. Synchronous getting to know refers to a researching event in which a group of scholars is engaged in research at the same time. Earlier than discovering generation permitted for synchronous researching surroundings, utmost online educations were over asynchronous discovering methods. Because synchronous equipment that can be implemented for education turns out to be obtainable, many americans are turning to them to assist cut the demanding situations related to the transactional distance that glad in online education. A few case experiences found that scholars can develop a neighborhood experience over online synchronous communique systems. (Nicholson, 2002)(Oztok, M., Zingaro, D., Brett, C., \& Hewitt, 2013)(Schwier, R. A., \& Balbar, 2002)(Hrastinski, 2006)

While many online tutorial courses began out in place and with the creation of online conferencing equipment, individuals can be told at the moment in various places. For instance, quick messaging or live chat, online seminars, and video conferences enable scholars and lecturers to cooperate and be told directly.

A talk is an instance of synchronous getting to know each other in an unpretentious atmosphere since they are together. An alternative instance of the synchronous researching event will include scholars looking at a reside natural web world of a lecture, whereas concurrently include in a dialogue. Synchronous studying can be smoothed by inviting scholars and teachers to participate in a class, not an online conference tool. The reproduction can be designed to develop and boost instructor-student and student-student relations, which can be a problem in detachment getting to know courses. (Orr, 2010)

\section{RESEARCH METHODS}

In this study, researchers used descriptive qualitative methods and took English teachers in Banjarmasin as research. The teachers were from states and private learning institutions like schools, colleges, and courses. The research was conducted by holding social media sharing, focused on WhatsApp, as a medium for learning English. The medium was used as exercise and 
games. Next, the researchers asked the subjects to use WhatsApp in the teaching and learning process. Next, researchers distributed questionnaires to figure out the perception of teachers. Finally, the research findings were described in the following section.

\section{FINDING AND DISCUSSION}

\section{Learning Activity Variation}

There are many variations of activities using the WhatsApp application that can be implemented in the classroom, but we focused on using WhatsApp in training and games in this study. Here are two screenshots of chat in-class learning activities.

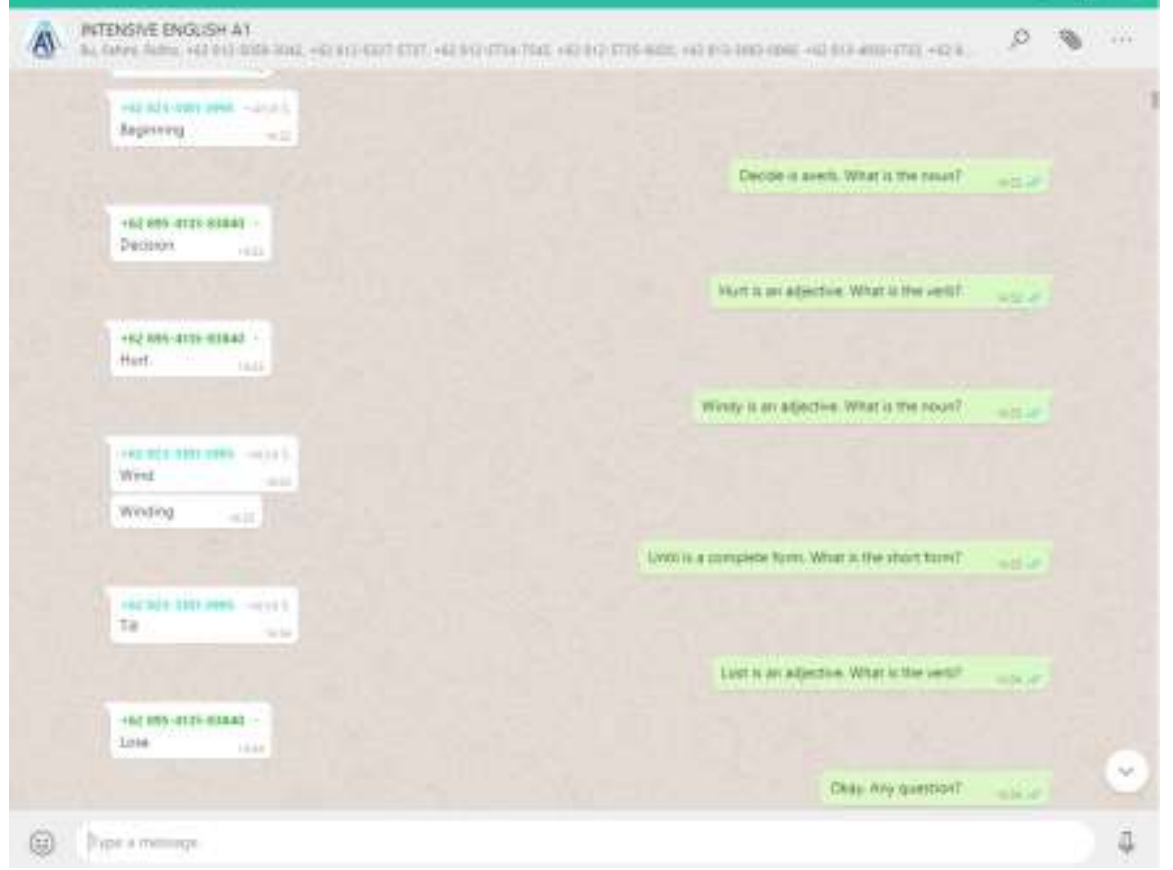




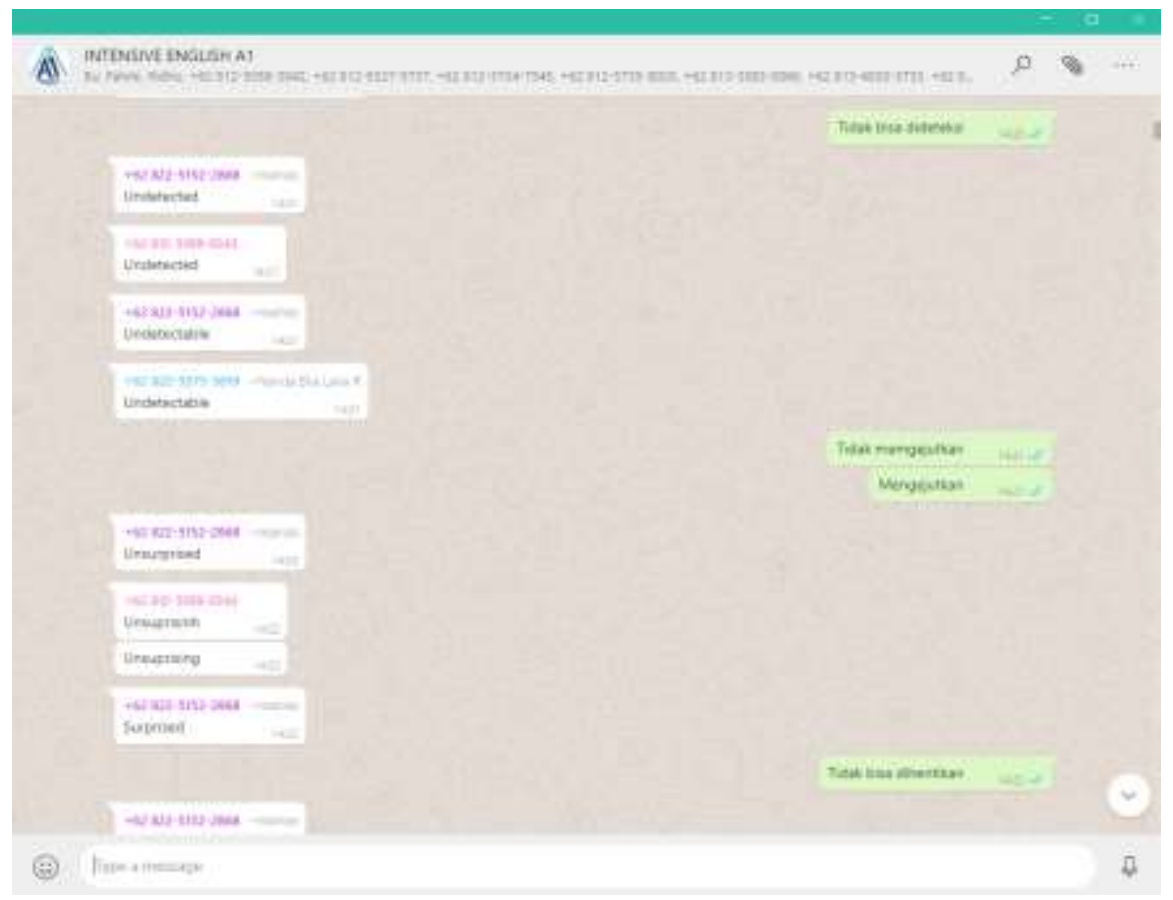

Image 1 Screenshot WhatsApp for game

The three activities that can be done using WhatsApp are as follows.

a. English word formation

activities that involve the formation of words can be done in the form of a WhatsApp group. Students are grouped into groups with a maximum of 4 students. Each group is only allowed to use one cellphone. After the grouping is complete, the teacher types a word and sends it to the chat group. Each group will type their answers. The group that will get the score is the group that can answer the fastest. For example, the teacher types "entertain," so students will answer "entertainment," entertaining," or" entertains." All words are new words made based on the words provided by the teacher. In addition to providing words, the teacher can also provide affixation only. Students will make a word based on the affixation given by the teacher.

b. English Sentence Structure

For structure, many activities can be done. Some of them are sentence completion. Like the previous activity, the teacher should group students so that cooperation is still built. The teacher makes incomplete sentences, and students will be asked to complete the sentence. For example, the teacher says, "I love the rain because ..." the student will continue the sentence so that it becomes complete and the meaning is perfect. Another variation is that the teacher will provide conjunction, and the student will make a sentence containing the conjunction.

c. English Expressions

Another activity that can be done is to practice remembering expressions for speaking class. In this case, the teacher will type expressions that students in groups must answer. For example, the teacher typed, "What should I call you?" Then students will answer by typing, "You can call me Jack." 


\section{Teacher's Perception}

After sharing and implementing the variation of the activities mentioned above, the researcher asked for perceptions from the English teachers. Their perception is as follows.

1) WhatsApp is beneficial as a learning medium.

Often students are reluctant to learn because of insufficient sources of learning. Adequate learning resources must support the curriculum related to self-development and career development. Reliable printed books, audio, video, exciting teaching media, so students are not saturated with the delivery of monotonous material. The more diverse and complete the resources available in the class, the greater the tendency of students to love learning.

Using WhatsApp is practical to learn English and develop the students' language skills. They are using exercise or games using WhatsApp; they are required to discuss, think, and decide on the answer at the same time. The discussion helps them to collaborate well since they can share their ideas. In addition, they helped them to learn from their colleagues' mistakes and helped them develop their writing skills. It is because they can learn only from their English teacher, but also from their friends. Not all students can understand the same way - some of the things that are just like them.

In addition, there are. Generally, each individual will feel proud if they have something more than others. Call it more innovative, more successful, better, and much more. Vice versa, people will feel sad if they are under someone else. For example, more stupid, lazy, always fail, and others. Well, from here, every person has the instinct to compete. Learning activities that involve games as a competition can provoke pride in students, so they will be eager to learn to compete with other students.

2) Students were motivated to follow the learning process because they used something they like.

As stated in the background, most students like spending their time on social media. One of the social media is WhatsApp. The purpose of teaching and learning activities in the classroom is to master students' competencies or learning objectives. The teacher's task is to manage to learn (from planning, implementation to assessment). It is intended so that students can achieve learning goals to the fullest. However, there are times when teachers cannot realize the achievement of these noble goals because of the shared passion of students to learn. The impact is certainly not good, of which students cannot master the competencies or objectives of the lesson. When a teacher uses something they like as a medium in the teaching and learning process, they fill the lesson enthusiastically. Learning by using media can make students happy.

Furthermore, in the end, students can capture the material. Learning media can also facilitate goals to understand and remember information or messages contained in the WhatsApp game. Teaching and learning activities also tend to be more interesting, and students will be addicted to the learning model applied by the teacher.

3) The use of WhatsApp can promote more interaction between students. 
Student-to-student interaction is a must-have part of any course hostile. In lecture room surroundings, this interplay occurs as scholars hear each other's feedback, ask each other questions, and construct rapport through frequent contact. Crew can additionally foster student-to-student interplay in an online surrounding; however, it may require constructing formal and casual interplay alternatives in the course design. Designing for a high level of student-to-student interplay online is so important that college accrediting teams of workers, like the center States fee on more advantageous education, require proof of it in the online course and program design. The interaction between students in learning makes students have a high level of socialization; solidarity between students becomes good. With socialization, students will also learn a lot related to social skills or social skills, such as politeness and respect for others. The use of the WhatsApp group in learning activities can make students interact in the classroom. It is because they have to discuss to be able to answer the questions given by the teacher. In this case, in addition to combining answers, they will also learn to divide tasks and responsibilities to answer correctly and correctly. According to the teachers, the use of WhatsApp is beneficial in triggering these interactions. However, they stated that this activity still requires supervision from the teacher because it is possible for students to use their

cellphone to do other things such as streaming or chatting that have nothing to do with the English game.

\section{CONCLUSION}

Based on the finding and discussion above, it can be concluded that:

1) WhatsApp was beneficial as a learning medium,

2) Students were motivated to follow the learning process because they used something they like,

3) the use of WhatsApp can also promote more interaction between students.

4) Teacher's supervision on the classroom activity involving WhatsApp is still required to make sure the activity runs smoothly.

\section{REFERENCES}

Alexander, S. \& McKenzie, J. (1998). An Evaluation of Information Technology Projects for University Learning. Canberra: Committee for University Teaching and Staff Development and the Department of Employment, Education, Training and Youth Affairs.

Alexander, S. (2010). Flexible Learning in Higher Education". In Penelope Peterson; Eva Baker; Barry McGaws. In International Encyclopedia of Education (Third ed.).

Bray, B. and K. M. (2012). Blended Learning is Not the Only Way to Personalize Learning.

Conference Abroad. (2016). The E-Learning Edge: Improving Access With Ontario Learn. 
Dale, B. (2014). "Personalized vs. differentiated vs. individualized learning. ISTE.

Friesen, N. (2012). Defining Blended Learning.

Garrison, D. R.; Kanuka, H. (2004). Blended learning: Uncovering its transformative potential in higher education. The Internet and Higher Education.

Harel Caperton, I. (2012). Learning to Make Games for Impact. Harel Caperton, Idit (2012). "Learning to Make Games for Impact." The Journal of Media Literacy.

Hartman, J.; Moskal, P. \& Dziuban, C. (2005). Preparing the Academy of today for the learner of tomorrow. Louisville: Educause Publications.

Heinze, A. C. P. (2005). "Online Communication and Information Technology Education. Journal of Information Technology Education.

Hrastinski, S. (2006). The relationship between adopting a synchronous medium and participation in online group work: An explorative study. Interactive Learning Environments, 14(2), 137-152.

Ingfei Chen. (2014). "For Frustrated Gifted Kids, A World of Online Opportunities. KQED.

Jacob, A. M. (2011). "Benefits and Barriers to the Hybridization of Schools. Journal of Education Policy, Planning, and Administration.

Knewton. (n.d.). No Title. In Blended Learning: A Disruptive Innovation.

Lothridge, K. (2013). Blended Learning: Efficient, Timely, and Cost-Effective. Journal of Forensic Sciences.

Mims-Word, M. (2016). Enhancing Students' Language Skills through Blended Learning. Electronic Journal of E-Learning, 14(3), 220-229.

https://doi.org/10.1504/IJTEL.2012.051816

Moskal, Patsy; Dziuban, Charles; Hartman, J. (2012). Blended learning: A dangerous idea? Internet and Higher Education.

Nicholson, S. (2002). Socialization in the "virtual hallway": instant messaging in the asynchronous web-based distance education classroom. The Internet and Higher Education, 5(4), 363372.

Oliver M, T. K. (2005). Can "Blended Learning" Be Redeemed? E-Earning and Digital Media.

Orr, P. (2010). Distance supervision: Research, findings, and considerations for art therapy. The Arts in Psychotherapy, 37, 106-111.

Oztok, M., Zingaro, D., Brett, C., \& Hewitt, J. (2013). Exploring asynchronous and synchronous tool use in online courses. Computers \& Education, 60(1), 87-94.

Peter Bradford; Margaret Porciello; Nancy Balkon; Debra Backus. (2007). THE BLACKBOARD LEARNING SYSTEM. The Journal of Educational Technology Systems. 
Saritepeci, M. et al. (2015). The effect of blended learning environments on student motivation and student engagement: A study on social studies course. Education and Science.

Schwier, R. A., \& Balbar, S. (2002). The interplay of content and community in synchronous and asynchronous communication: Virtual communication in a graduate seminar. Canadian Journal of Learning and Technology, 28(2).

Siemens, G., Gašević, D., \& Dawson, S. (2015). Preparing for the Digital University: a review of the history and current state of distance, blended, and online learning. Athabasca University.

Staker, B. H., \& Horn, M. B. (2012). Blended Learning (Staker / Horn - May 2012), (May). https://doi.org/10.1007/s10639-007-9037-5

Strauss, V. (2012). No TitleThree Fears about Blended Learning. 